\title{
Full genome sequencing to study the evolutionary characteristics of foot-and-mouth disease virus in southern Africa
}

Authors:

Christopher J. Kasanga ${ }^{1}$

Begoña Valdazo-González ${ }^{2}$

Rahana Dwarka ${ }^{3}$

Jemma Wadsworth ${ }^{2}$

Nick J. Knowles ${ }^{2}$

Philemon N. Wambura ${ }^{1}$

Mark M. Rweyemamu ${ }^{1}$

Misheck Mulumba ${ }^{4}$

Jimis Deve ${ }^{5}$

Donald P. King ${ }^{2}$

\section{Affiliations:}

${ }^{1}$ Southern African Centre

for Infectious Diseases

Surveillance, Sokoine

University of Agriculture,

Tanzania

${ }^{2}$ WRLFMD, The Pirbright Institute, United Kingdom

${ }^{3}$ Onderstepoort Veterinary Institute, University of

Pretoria, South Africa

${ }^{4}$ Southern African

Development Community

Secretariat, Botswana

${ }^{5}$ Ministry of Agriculture and Livestock, Mozambique

\section{Correspondence to:}

Christopher Kasanga

Email:

christopher.kasanga@sacids. org

Postal address:

PO Box 3019, Chuo Kikuu,

Morogoro, Tanzania

How to cite this article: Kasanga, C.J., ValdazoGonzález, B., Dwarka, R., Wadsworth, J., Knowles, N.J., Wambura, P.N. et al., 2014, 'Full genome sequencing to study the evolutionary characteristics of foot-and-mouth disease virus in southern Africa', Onderstepoort Journal of Veterinary Research 81(2), Art. \#729, 1 page. http://dx.doi. org/10.4102/ojvr.v81i2.729

\section{Read online:}

Scan this QR code with your smart phone or mobile device to read online.
Foot-and-mouth disease (FMD) is endemic in most countries of southern Africa where it affects cloven-hoofed animals that include livestock and wildlife. Southern Africa relies profoundly on livestock production as a source of economic growth and livelihoods. Despite the importance of FMD in southern Africa, the epidemiology of FMD virus (FMDV) and factors contributing to the endemicity of FMD infection in susceptible animal populations are not clearly known in this region. In this study, we designed and optimised an RT-PCR strategy for amplification of the complete genome of FMDV SAT 1, and sequenced the whole genome of one isolate, designated SAT1/MOZ/BUF-B16/2010, which was isolated from an African buffalo (Syncerus caffer) in Mozambique in 2010. Preliminary analyses showed that the genome polyprotein of SAT1/MOZ/ BUF-B16/2010 consisted of 7626 nucleotides. Alignment of nucleotides and deduced amino acid sequences and phylogenetic analysis indicated that the virus is closely related to SAT 1 strains from the southern African region. Using a FASTA search, the polyprotein showed closest nucleotide identity (94\%) to SAT1/RHO/5/66 isolated from cattle in Devuli ranch in southeast Zimbabwe in 1966. This RT-PCR and whole genome sequencing strategy could be deployed to study the evolutionary characteristics of viruses sampled from cattle and buffalo at different locations in time and space. A full repertoire of protocols for all of the circulating FMDV lineages is now required to conduct an in-depth genome analysis to understand the factors that impact upon FMDV endemicity in the region. This information is necessary for strategies for the control of FMD in most countries in Africa. The genome sequencing approach allows for targeted and cost-effective FMD control strategies in the endemic settings of Africa rather than application of blanket and expensive interventions - an important consideration for resource constrained countries.

\section{Acknowledgements}

This work was supported by the Wellcome Trust Grant WT087546MA to the Southern African Centre for Infectious Diseases \& Surveillance (SACIDS).

Note: Proceedings of the 2 nd One Health Conference in Africa. Jointly organised by the Southern African Centre for Infectious Disease Surveillance and the Tanzania National Institute for Medical Research, held at the Snow Crest Hotel in Arusha, Tanzania from 16th to 19 th April 2013: http://www.sacids.org/kms/frontend/index.php?m=119.

Copyright: (C 2014. The Authors. Licensee: AOSIS OpenJournals. This work is licensed under the Creative Commons Attribution License. 